\title{
PERANCANGAN APLIKASI SURAT KETERANGAN PENDAMPING IJAZAH BERBASIS WEB PADA STMIK JAYAKARTA
}

\author{
Zulhalim $^{1}$, Anton Zulkarnain Sianipar ${ }^{2}$, Edi Witono ${ }^{3}$ \\ Sistem Informasi ${ }^{1}$, Teknik Informatika ${ }^{2}$, Teknik Informatika ${ }^{3}$ \\ STMIK Jayakarta ${ }^{1}$, STMIK Jayakarta ${ }^{2}$, STMIK Jayakarta ${ }^{3}$ \\ zulhalim@stmik.jayakarta.ac.id ${ }^{1}$, anton@stmik.jayakarta.ac.id ${ }^{2}$, edinicov@gmail.com ${ }^{3}$
}

\begin{abstract}
ABSTRAK
Penerapan Surat Keterangan Pendamping Ijazah (SKPI) kepada setiap lulusan atau calon sarjana baru merupakan amanat kurikulum berbasis Kerangka Kualifikasi Nasional Indonesia (KKNI). Hal itu dilakukan agar setiap lulusan perguruan tinggi di samping memiliki ijazah formal juga memiliki SKPI yang terkait dengan keahlian tertentu. Tujuan dari penelitian ini adalah mendesain, merancang dan membuat aplikasi sistem e-SKPI pada STMIK Jayakarta. Metode pengembangan aplikasi ini menggunakan metode Extreme Programning dengan permodelan UML dan bahasa pemrograman web PHP menggunakan framework Laravel. Dengan sistem e-SKPI ini, semua mahasiswa STMIK Jayakarta yang sudah menyelesaikan tugas akhirnya dapat menginputkan dan mengupload semua sertifikat yang terkait dengan bidang ilmunya. Program studi dapat melakukan verifikasi dan menghasilkan SKPI ini secara online untuk diberikan kepada para lulusan. Dengan adanya sistem e-SKPI ini diharapkan dapat mempermudah mahasiswa memperoleh SKPI dan akademik untuk mengelola dan mengadministrasikan penerbitan SKPI.
\end{abstract}

Kata kunci: Surat Keterangan Pendamping Ijazah, E-SKPI, Extreme Programming, Framework Laravel

\begin{abstract}
The applicatoin of Diploma Suplement (SKPI) to every graduate or prospective new graduate is mandated by the curriculum based on the Indonesian National Qualification Framework (KKNI). This is done so that each college graduate besides having a formal diploma also has an SKPI related to a particular expertise. The purpose of this research is to design, design and create an e-SKPI system application at STMIK Jayakarta. The application development method uses the Extreme Programning method with UML modeling and the PHP web programming language uses the Laravel framework. With this e-SKPI system, all Jayakarta STMIK students who have completed their assignments can finally input and upload all certificates related to their fields of science. Study programs can verify and produce these SKPI online to be given to graduates. With the existence of the e-SKPI system, it is expected to make it easier for students to obtain SKPI and academics to manage and administer SKPI issuance.
\end{abstract}

Keywords: Diploma Suplement Letter, E-SKPI, Extreme Programming, Laravel Frameworks

\section{PENDAHULUAN}

Salah satu langkah strategis yang dilakukan Pemerintah dalam mengantisipasi pengakuan kualifikasi ketenagakerjaan dan pendidikan di Indonesia adalah dengan menyusun Kerangka Kualifikasi Nasional Indonesia (KKNI) dalam bentuk Peraturan Presiden Republik Indonesia Nomor 8 tahun 2012 [1] dan kemudian diperkuat oleh UU Nomor 12 tahun 2012 tentang Pendidikan Tinggi. Sesuai yang tertuang pada pasal 1 ayat 17 UU RI Nomor 20 Tahun 2003 [2]; bahwa "Standar nasional pendidikan adalah kriteria minimal tentang sistem pendidikan di seluruh wilayah hukum Negara Kesatuan Republik Indonesia". Mengenai kriteria minimal standar nasional pendidikan ini terdiri atas standar isi, proses, kompetensi lulusan, tenaga kependidikan, sarana dan prasarana, pengelolaan, pembiayaan, dan penilaian pendidikan yang harus ditingkatkan secara berencana. Implementasi KKNI dimulai dengan proses mendeskripsikan kualifikasi lulusan suatu program pendidikan secara jelas dan terukur serta secara transparan agar dapat dipahami oleh pihak penghasil dan pengguna tenaga kerja baik di tingkat nasional, regional maupun internasional.

Bentuk kongkrit untuk pendeskripsian capaian pembelajaran tersebut, adalah dengan menerbitkan Surat Keterangan Pendamping Ijazah (SKPI) sejak Agustus 2014, berdasarkan Permendikbud No. 73 Tahun 2013 [3],

JISICOM (Journal of Information System, Informatics and Computing) http://journal.stmikjayakarta.ac.id/index.php/jisicom Telp.+62-21-3905050, e-mail:jisicom@stmikjayakarta.ac.id, jisicom2017@gmail.com 


\section{Journal of Information System, Informatics and Computing}

Permendikbud No. 49 Tahun 2014, dan Permendikbud No. 81 Tahun 2014 [4]. Dengan terbitnya SKPI, maka implementasi kebijakan KKNI tersebut secara substansial mendorong pengembangan sistem penjaminan mutu yang mampu melakukan fungsi pemantauan (monitoring) dan pengkajian (assessment) terhadap Perguruan Tinggi penghasil lulusan.

Perguruan Tinggi menerbitkan SKPI berdasarkan pencapaian pembelajaran mahasiswa selama menempuh perkuliahan. Prosedur ini mengharuskan pihak program studi untuk menelaah setiap lulusannya. Sekolah Tinggi Manajemen Informatika dan Komputer (STMIK) Jayakarta menerbitkan dokumen SKPI masih secara manual. Berdasarkan hal tersebut, untuk mewujudkan proses penerbitan SKPI diperlukan sebuah sistem operasional prosedur (SOP) dan sistem secara online yang dapat membantu para lulusan dan program studi. Dengan sistem E-SKPI ini, semua mahasiswa yang telah menyelesaikan tugas akhirnya dapat menginputkan kegiatan kemahasiswaan serta mengupload semua sertifikat yang terkait dengan bidang ilmunya. Kemudian program studi dapat melakukan verifikasi dan menghasilkan SKPI ini secara online untuk diberikan kepada para lulusan.

\section{METODE DAN MATERI}

\subsection{Metode Pengumpulan Data}

Dalam proses pengumpulan data penulis menggunakan metode: a) Observasi, teknik mendapatkan data primer dengan mengamati langsung obyek datanya. Pada penelitian ini, observasi dilakukan dengan pengamatan secara langsung proses pengelolaan dan pengadministrasian penerbitan dokumen SKPI di lingkungan STMIK Jayakarta; b) Wawancara, komunikasi dua arah untuk mendapatkan data daru responden. Wawancara dilakukan untuk mengkonfirmasi data atau fakta yang diperoleh pada saat observasi serta sekaligus untuk menggali software requirement dari pengguna. Pada penelitian ini, wawancara dilakukan secara langsung dengan karyawan bagian Akademik pada STMIK Jayakarta selaku pengguna dan pemilik proses bisnis pengelolaan dan pengadministrasian penerbitan dokumen SKPI; c) Studi Pustaka mengumpulkan data dan informasi melalui dokumen-dokumen baik dalam bentuk buku, jurnal, prosiding, laporan-laporan, atau bentukbentuk lain dalam bentuk tercetak maupun digital. Pada penelitian ini, studi pustaka dilakukan dengan membaca buku-buku literatur, laporan penelitian lain, serta jurnal yang berhubungan dengan perancangan sistem aplikasi dan peraturan-peraturan yang berkaitan dengan penerbitan dokumen SKPI.

\subsection{Metode Pengembangan Sistem}

Metode yang dipakai untuk perancangan sistem dalam penelitian ini adalah Agile Software Development Methods dengan pendekatan model Extreme Programming (XP). XP melakukan setiap aktivitas pengembangan perangkat lunak hampir secara bersamaan. Analisis, perancangan, pengkodean, pengujian, dan bahkan penyebaran berlangsung dengan frekuensi yang cepat. Aktivitas-aktivitas tersebut dilakukan secara bersamaan dan dikerjakan dalam iterasi. Pada metode dan pendekatan ini terdapat beberapa langkah sebagai berikut: a) Perencanaan (planning), tahapan ini dimulai dengan mendengarkan kumpulan kebutuhan aktifitas suatu sistem yang memungkinkan pengguna memahami proses bisnis untuk sistem dan mendapatkan gambaran yang jelas mengenai fitur utama, fungsionalitas dan keluaran yang diinginkan; b) Analisis (analysis), pada tahapan ini dilakukan analisis kebutuhan-kebutuhan untuk perangkat lunak yang dikembangkan berdasarkan gambaran dari proses bisnis, fitur utama, fungsionalitas dan keluaran yang diharapkan, pada tahap ini disusun juga sketsa tampilan antar muka pengguna dari aplikasi yang dikembangkan; c) Perancangan dan pengkodean (design \& coding) pada tahapan perancangan dilakukan pembuatan pemodelan sistem berdasarkan hasil analisa kebutuhan yang didapatkan, selain itu dibuatkan juga pemodelan basis data untuk menggambarkan hubungan antar data, kemudian rancangan model sistem yang telah dibuat diimplementasikan ke dalam kode program yang menghasilkan prototipe dari perangkat lunak; d) Pengujian (testing), tahapan ini merupakan tahapan pengujian terhadap aplikasi yang sudah dibangun, pada tahapan ini ditentukan oleh pengguna sistem dan berfokus pada fitur dan fungsionalitas dari keseluruhan sistem kemudian ditinjau oleh pengguna sistem; dan e) Penyebaran (deployment), Tahapan ini merupakan tahap penyebaran perangkat lunak yang telah lolos tahap pengujian kepada pengguna, dalam tahap ini dilakukan juga pemantauan dan evaluasi terhadap perangkat lunak yang sudah dibuat secara bertahap apakah ditemukan kesalahan sistem atau penambahan layanan atau konten yang mengakibatkan bertambahnya kemampuan fungsionalitas dari sistem [5].

\subsection{Kerangka Kualifikasi Nasional Indonesia}

Menurut Peraturan Menteri Pendidikan Dan Kebudayaan Republik Indonesia Nomor 73 Tahun 2013 Tentang Penerapan Kerangka Kualifikasi Nasional Indonesia Bidang Pendidikan Tinggi, Kerangka Kualifikasi Nasional Indonesia (KKNI) bidang pendidikan tinggi merupakan kerangka penjejangan 


\section{Journal of Information System, Informatics and Computing}

kualifikasi yang dapat menyandingkan, menyetarakan, dan mengintegrasikan capaian pembelajaran dari jalur pendidikan nonformal, pendidikan informal, dan/atau pengalaman kerja ke dalam jenis dan jenjang pendidikan tinggi.

Penjenjangan kualifikasi tersebut dimaksudkan untuk memfasilitasi pendidikan seseorang yang mempunyai pengalaman kerja atau memiliki capaian pembelajaran dari pendidikan nonformal atau pendidikan informal untuk menempuh pendidikan formal ke jenjang/tingkat yang lebih tinggi dan/atau untuk mendapatkan pengakuan kualifikasi lulusan jenis pendidikan tertentu dari perguruan tinggi.

Capaian pembelajaran pendidikan nonformal, pendidikan informal, dan pengalaman kerja dapat disetarakan dengan jenjang kualifikasi tertentu pada pendidikan tinggi. Penyetaraan capaian pembelajaran tersebut diberlakukan mulai dari jenjang kualifikasi 3 (tiga) sebagai jenjang paling rendah sampai dengan jenjang kualifikasi 9 (sembilan) sebagai jenjang paling tinggi. Jenjang kualifikasi tersebut mempunyai kesetaraan dengan jenjang pendidikan formal adalah a) Jenjang 3 setara dengan lulusan diploma 1; b) Jenjang 4 setara dengan lulusan diploma 2; c) Jenjang 5 setara dengan lulusan diploma 3; d) Jenjang 6 setara dengan lulusan diploma 4 atau sarjana terapan dan sarjana; e) Jenjang 7 setara dengan lulusan pendidikan profesi; f) Jenjang 8 setara dengan lulusan magister terapan, magister, atau spesialis satu; g) Jenjang 9 setara dengan lulusan pendidikan doktor terapan, doktor, atau spesialis dua [3].

\subsection{Surat Pendamping Ijasah}

Surat Keterangan Pendamping Ijazah (SKPI) menurut Peraturan Menteri Pendidikan dan Kebudayaan Republik Indonesia Nomor 81 Tahun 2014 tentang ijazah, sertifikat profesi dan sertifikat kompetensi perguruan tinggi, pada Bab I pasal 1 menuliskan SKPI adalah dokumen yang memuat informasi tentang pencapaian akademik atau kualifikasi dari lulusan pendidikan tinggi bergelar.

SKPI adalah bentuk kongkrit dari pendiskripsian dari kualifikasi lulusan suatu program pendidikan secara jelas dan terukur serta secara transparan agar dapat dipahami oleh pihak penghasil dan pengguna tenaga kerja baik di tingkat nasional, regional maupun internasional yang merupakan implementasi kebijakan Kerangka Kualifikasi Nasional Indonesia (KKNI).

Menurut pasal 7 ayat 1 Peraturan Menteri Pendidikan dan Kebudayaan Republik Indonesia Nomor 81 Tahun 2014 SKPI harus memuat a) Logo dan Kop Surat Perguruan tinggi; b) Informasi tentang identitas diri pemegang SKPI: Nama Lengkap, Tempat dan tanggal lahir, Nomor Induk Mahasiswa, Tahun Masuk, Tahun
Lulus, Nomor Ijazah, Gelar/sebutan lulusan; c) Informasi tentang identitas Penyelenggara Program: Nama Perguruan Tinggi, Status Akreditasi Perguruan Tinggi saat SKPI ditandatangani, Nomor SK Akreditasi Perguruan Tinggi saat SKPI ditandatangani, Nama Program Studi, Status Akreditasi Program Studi saat SKPI ditandatangani, Nomor SK Akreditasi Program Studi saat SKPI ditandatangani, Jenis pendidikan (akademik, vokasi, atau profesi), Jenjang pendidikan, Jenjang kualifikasi sesuai KKNI, Persyaratan penerimaan, Bahasa pengantar kuliah, Sistem penilaian (Uraian gradasi penilaian dan penjelasannya), Lama studi regular, Jenis dan jenjang pendidikan lanjutan, Status profesi (bila ada); d) Informasi tentang isi kualifikasi dan hasil yang dicapai; e) Sistem pendidikan tinggi di Indonesia dan Kerangka kualifikasi Nasional Indonesia; f) Pengesahan SKPI, Tanggal, Tandatangan, Nama Jelas, Jabatan (minimal Dekan), Nomor Identifkasi pejabat penandatangan, Cap PT (official stamp); g) Akuntabilitas SKPI; h) Lampiran; dan i) Akuntabilitas Lampiran SKPI [4].

\subsection{Aplikasi Berbasis Web}

Menurut Simarmata, aplikasi berbasis web adalah sistem perangkat lunak yang berdasarkan pada teknologi dan standar World Wide Web Consortium (W3C). Mereka menyediakan sumber daya web spesifik seperti konten dan layanan melalui sebuah antarmuka pengguna dan browser web. Aplikasi berbasis Web ini menggunakan protokol HTTP, aplikasi di sisi server berkomunikasi dengan client melalui Web server. Aplikasi di sisi client umumnya berupa aplikasi Web browser. Pada umumnya, web bekerja pada arsitektur Client/Server. Client/Server dapat diartikan sebagai kemampuan komputer untuk meminta layanan request data kepada komputer lain. Komputer yang meminta layanan disebut sebagai client, sedangkan yang menyediakan layanan disebut sebagai server.

Komputer client melakukan permintaan suatu informasi atau mengirim perintah ke server. Server menerima permintaan dan perintah client. Kemudian server memproses berdasarkan permintaan tersebut, dan mengembalikan kepada client sebagai hasil pemrosesan yang sudah dilakukan. Service Request adalah permintaan dari client baik berupa permintaan data maupun perintah ke server. Service Response berupa balasan dari server atas permintaan dari client berupa hasil proses [6].

\subsection{Framework Laravel}

Laravel adalah salah satu framework PHP terbaik yang dikembangkan oleh Taylor Otwell. Laravel dapat membantu Anda untuk memaksimalkan penggunaan PHP 


\section{Journal of Information System, Informatics and Computing}

di dalam proses pengembangan website. PHP menjadi bahasa pemrograman yang sangat dinamis, tapi semenjak adanya Laravel, dia menjadi lebih powerful, cepat, aman, dan simpel. Setiap rilis versi terbaru, Laravel selalu memunculkan teknologi baru di antara framework PHP lainnya. Laravel diluncurkan sejak tahun 2011 dan mengalami pertumbuhan yang cukup eksponensial. Di tahun 2015, Laravel adalah framework yang paling banyak mendapatkan bintang di Github. Sekarang framework ini menjadi salah satu yang populer di dunia, tidak terkecuali di Indonesia [7].

\subsection{Telaah Pustaka}

Beberapa penelitan terdahulu yang mendukung dan berkaitan dengan perancangan sistem antara lain: a) Sinta Eka Fitriyanti, Sistem Informasi SKPI Sebagai Penunjang Kebutuhan Stakeholder tahun 2019, Mengembangkan sistem informasi SKPI sebagai penunjang kebutuhan stakeholder dengan menerapkan sistem berbasis web serta menerapkan metode pengembangan sistem prototype [8]; b) Des Suryani, Ause Labellapansa, Hendra Gunawan, ESKPI Fakultas Teknik Universitas Islam Riau tahun 2018, Telah dibangun sistem ESKPI pada Fakultas Teknik Universitas Islam Riau [9]; c) Efmi Maiyana, Teri Mengkasrinal, Pengembangan Sistem Informasi Surat Keterangan Pendamping Ijazah Berbasis Web dan Mobile Android tahun 2017, Dalam pembuatan SKPI dapat dilakukan dengan memanfaatkan teknologi informasi. SKPI dapat dirancang dengan menggunakan Bahasa pemrograman berbasis web dengan PHP/MySQL dan berbasis Mobile Android dengan tujuan memudahkan perguruan tinggi, juga dapat menghasilkan data yang akurat, tampilan yang menarik serta terhidar dari kehilangan data [10]; d) Defni, Fathur Ridha Fadly, Perancangan Sistem Informasi Surat Keterangan Pendamping Ijazah pada Politeknik Negeri Padang Berbasis Web tahun 2017, Telah disusun rancangan sistem informasi SKPI berbasis web pada Politeknik Negeri Padang [11] dan e) Anita, Daniel Rudiaman Sijabat, Sistem Informasi Kompetensi Mahasiswa guna Mendukung Lulusan dalam Mencari Kerja tahun 2017, Telah dibangun sistem informasi kompetensi mahasiswa berbasis web untuk penerbitan SKPI Mahasiswa pada STIKI Malang [12].

\section{PEMBAHASAN DAN HASIL \\ 3.1 Perencanaan}

STMIK Jayakarta didirikan dalam rangka menjawab tantangan dan perkembangan pesat dalam bidang informasi, di awal tahun 1990-an dan Yayasan Dharma Pendidikan Jakarta mendirikan Akademi Manajemen Informatika dan Komputer Jayakarta (AMIK Jayakarta) yang selanjutnya berdasarkan SK. Mendikbud Nomor 159/D/0/1993 ditingkatkan menjadi Sekolah Tinggi Manajemen Informatika dan Komputer Jayakarta (STMIK Jayakarta), yang memiliki jurusan Manajemen Informatika dan Teknik Informatika. STMIK Jayakarta memiliki 3 (tiga) program studi masing masing D.3 Manajemen Informatika, S.1 Manajemen Informatika dan S.1 Teknik Informatika.

Program Studi S.1 Manajemen Informatika dan S.1 Teknik Informatika memperoleh status "diakui" dengan SK.216/DIKTI/Kep/1997, dengan adanya perubahan waktu sesuai dengan perkembangan teknologi maka untuk Program Studi S1 Manajemen Informatika berubah nama menjadi Sistem Informasi yang dibuat SKnya dalam perpanjangan Ijin Operasional, D.3-Manajemen Informatika memperoleh status "disamakan" dengan SK.23/DIKTI/Kep/1999. Sementara itu pihak Yayasan juga sudah memperoleh status "Terakreditasi" bagi seluruh program studi di STMIK Jayakarta dari Badan Akreditasi Nasional (BAN PTS), hal ini sudah diwujudkan dalam hasil Akreditasi dan sudah terealisasi melalui Keputusan Badan Akreditasi Nasional Perguruan Tinggi Kemenristek, sebagai berikut: a) D3. Manajemen Informatika: No. 500/SK/BAN-PT/Akred/Dpl-III/V/2015 - 03 Mei 2020 Akreditasi B; b) S1. Sistem Informasi: No.2458/SK/BAN PT/Akred/S/X/2016 - 21 Oktober 2021 Akreditasi B; dan c) S1.Teknik Informatika: No. 1262/SK/BAN-PT/Akred/S/XII/2015 - 29 Desember 2020 Akreditasi B [13].

Berdasarkan Peraturan Menteri Pendidikan dan Kebudayaan Republik Indonesia Nomor 81 Tahun 2014 tentang Ijazah, Sertifikat Kompetensi, dan Sertifikat Profesi Pendidikan Tinggi, STMIK Jayakarta diharuskan mempunyai sistem yang cepat, tepat dan efisien dalam pelayanan penerbitan dokumen SKPI untuk para lulusannya. Pembuatan sistem aplikasi yang online mampu untuk menjawab tantangan tersebut, sekaligus sebagai pengawasan dan validasi dalam penerbitan SKPI, serta untuk mempermudah administrasi/arsip dokumendokumen pendukung penerbitan SKPI, karena tidak lagi menggunakan berkas/hard copy

\subsection{Analisis}

Analisis SWOT (Strength, Weakness, Opportunities \& Threat) bertujuan untuk mengidentifikasi faktor internal sistem yang telah ada dalam Perguruan Tinggi sebagai kekuatan dan kelemahan, serta faktor eksternal sistem sebagai peluang dan ancaman. Selanjutnya dengan hasil identifikasi ini dapat disusun strategi untuk memperbaiki atau membuat sistem baru dalam meningkatkan daya saing dengan Perguruan Tinggi lain di pasar global. Dari hasil observasi dan wawancara yang 


\section{Journal of Information System, Informatics and Computing}

telah dilakukan penulis, dapat diidentifikasi faktor-faktor internal dan eksternal sistem pada STMIK Jayakarta, sebagai berikut:

\begin{tabular}{|c|c|c|}
\hline \multirow[b]{2}{*}{ Ekstemal } & $\begin{array}{c}\text { Strenghts (S) } \\
\text { (Kekuatan) }\end{array}$ & \multirow{2}{*}{\begin{tabular}{|l}
\multicolumn{1}{|c}{$\begin{array}{c}\text { Weakness (WV) } \\
\text { (Kelemahan) }\end{array}$} \\
Belum memiliki sistem \\
Aplikasi SKPI berbasis \\
web online
\end{tabular}} \\
\hline & 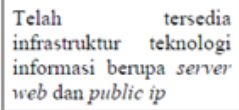 & \\
\hline $\begin{array}{c}\text { Opportunities (O) } \\
\text { (Peluang) }\end{array}$ & Strategi SO : & Strategi WO : \\
\hline $\begin{array}{l}\text { Perkembangan } \\
\text { Teknologi Informasi } \\
\text { yang semakin pesat, } \\
\text { memungkinkan untuk } \\
\text { membangun sistem } \\
\text { Aplikasi SKPI berbasis } \\
\text { web online }\end{array}$ & $\begin{array}{l}\text { Meningkatkan } \\
\text { pemanfaatan } \\
\text { infrastruktur Teknologi } \\
\text { Informasi yang telah ada }\end{array}$ & $\begin{array}{lr}\text { Meningkatkan pelayanan } \\
\text { dan kemudahan } & \text { kepada } \\
\text { mahasiswa } & \text { dalam } \\
\text { pengajuan } & \text { penerbitan } \\
\text { SKPI } & \\
\text { Simplifikasi } & \text { dan } \\
\text { Otomatisasi } & \text { Sistem } \\
\text { penerbitan SKPI } & \end{array}$ \\
\hline $\begin{array}{l}\text { Threats }(T) \\
\text { (Ancaman) }\end{array}$ & Strategi ST: & Strategi TW : \\
\hline $\begin{array}{l}\text { Semakin banyak } \\
\text { Universitas/Perguruan } \\
\text { Tinggi yang telah } \\
\text { memiliki layanan } \\
\text { penerbitan SKPI secara } \\
\text { online }\end{array}$ & $\begin{array}{l}\text { Memanfaatkan sumber } \\
\text { daya yang ada untuk } \\
\text { meningkatkan daya saing } \\
\text { dengan Universitas } \\
\text { Perguruan Tinggi lain } \\
\text { dalam hal layanan } \\
\text { Teknologi Informasi }\end{array}$ & $\begin{array}{l}\text { Memiliki nilai tambah } \\
\text { dalam hal layanan } \\
\text { teknologi informasi }\end{array}$ \\
\hline
\end{tabular}

Berdasarkan analisis proses sistem yang berjalan pada STMIK Jayakarta, dapat disimpulkan kelemahankelemahan sebagai berikut: a) Sistem yang berjalan saat ini karena masih menggunakan Microsoft Excel, sehingga terdapat kemungkinan duplikasi data, karena tidak adanya validasi secara otomatis; b) sistem yang berjalan saat ini hanya bisa diakses oleh staf pengguna komputer yang terdapat file excel tersebut, sehingga apabila staf lain akan membuat dokumen SKPI harus meng-copy dari komputer tersebut ke perangkat lain; c) dalam sistem yang berjalan saat ini, pengelolaan dokumen SKPI beserta lampiranlampirannya masih dilakukan secara manual menggunakan bundle berkas/hard copy, sehingga tidak efektif dan efisien karena mahasiswa harus datang ke bidang Akademik untuk mengajukan penerbitan SKPI dengan membawa berkas/hard copy, serta pihak Akademik harus mengarsip berkas tersebut.

\subsection{Perancangan dan Pengkodean}

Perancangan sebuah sistem Aplikasi SKPI berbasis web online dapat menjadi solusi atas permasalahan dan memperbaiki kelemahan-kelemahan yang terdapat dalam sistem yang telah berjalan tersebut. Dengan adanya sistem Aplikasi SKPI berbasis web online, penerbitan SKPI akan semakin cepat, tepat dan efisien, validasi data dilakukan secara otomatis dalam sistem untuk menghindari duplikasi data. Semua staf bidang Akademik yang bertugas dan memiliki akses ke dalam sistem Aplikasi SKPI dapat menjalankan dan memproses penerbitan SKPI dari komputer masing-masing. Mahasiswa tidak perlu lagi membawa bundel berkas/hard copy lampiran pendukung SKPI, karena dapat di-upload ke dalam sistem secara online. Pengarsipan dokumen SKPI beserta lampiran pendukungnya dilakukan secara otomatis oleh sistem dalam bentuk soft copy.

Perancangan Sistem Aplikasi SKPI berbasis web ini dilakukan menggunakan alat-bantu UML (Unified Modeling Language), yaitu dengan merancang fungsionalitas sistem, diantaranya: a). Use Case Diagram; b) Activity Diagram; c). Sequence Diagram; d) Class Diagram dan e) Deployment Diagram.

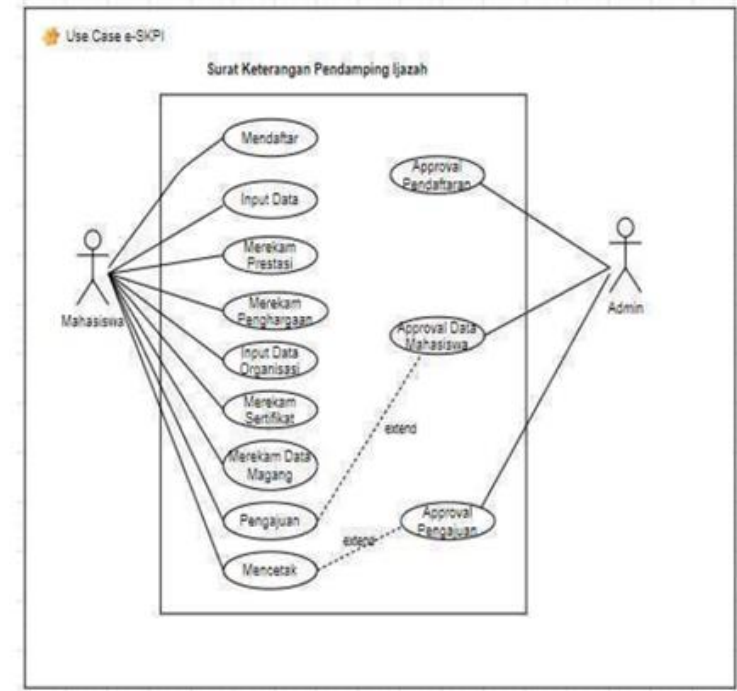

Gambar 3.1 Use Case Diagram

\begin{tabular}{|l|l|l|}
\hline Use Case & Actor & Deskripsi \\
\hline $\begin{array}{l}\text { Pendaftaran/ } \\
\text { Usegistrasi }\end{array}$ & $\begin{array}{l}\text { Mahasi } \\
\text { swa }\end{array}$ & $\begin{array}{l}\text { Mahasiswa yang belum } \\
\text { memiliki user aplikasi e- } \\
\text { SKPI melakukkan } \\
\text { registrasi pada aplikasi }\end{array}$ \\
\hline $\begin{array}{l}\text { Persetujuan/ } \\
\text { Approval } \\
\text { Pendaftaran }\end{array}$ & Admin & $\begin{array}{l}\text { Admin melakukan } \\
\text { approval/persetujuan } \\
\text { pendaftaran user baru }\end{array}$ \\
\hline Input Data & $\begin{array}{l}\text { Mahasi } \\
\text { swa }\end{array}$ & $\begin{array}{l}\text { Mahasiswa yang telah } \\
\text { memilikiuser, melakukan } \\
\text { perekaman data } \\
\text { profil mahasiswa }\end{array}$ \\
\hline $\begin{array}{l}\text { Merekam } \\
\text { Prestasi }\end{array}$ & $\begin{array}{l}\text { Mahasi } \\
\text { swa }\end{array}$ & $\begin{array}{l}\text { Mahasiswa yang telah } \\
\text { memiliki user, } \\
\text { melakukan perekaman } \\
\text { data prestasi dan } \\
\text { mengunggah dokumen } \\
\text { pendukungnya }\end{array}$ \\
\hline $\begin{array}{l}\text { Merekam } \\
\text { Penghargaa } \\
\text { n }\end{array}$ & $\begin{array}{l}\text { Mahasi } \\
\text { swa }\end{array}$ & $\begin{array}{l}\text { Mahasiswa yang telah } \\
\text { memiliki user,melakukan } \\
\text { perekaman data }\end{array}$ \\
\hline
\end{tabular}




\section{Journal of Information System, Informatics and Computing}

\begin{tabular}{|c|c|c|}
\hline & & $\begin{array}{l}\text { penghargaan dan } \\
\text { mengunggah dokumen } \\
\text { pendukungnya }\end{array}$ \\
\hline $\begin{array}{l}\text { Input Data } \\
\text { Organisasi }\end{array}$ & $\begin{array}{l}\text { Mahasi } \\
\text { swa }\end{array}$ & $\begin{array}{l}\text { Mahasiswa yang telah } \\
\text { memiliki user,melakukan } \\
\text { perekaman data peranan } \\
\text { dalam suatu organisasi } \\
\text { dan mengunggah } \\
\text { dokumen pendukungnya }\end{array}$ \\
\hline $\begin{array}{l}\text { Merekam } \\
\text { Sertifikat }\end{array}$ & $\begin{array}{l}\text { Mahasi } \\
\text { swa }\end{array}$ & $\begin{array}{l}\text { Mahasiswa yang telah } \\
\text { memiliki user,melakukan } \\
\text { perekaman data } \\
\text { sertifikat diklat / keahlian } \\
\text { dan mengunggah } \\
\text { dokumen pendukung / } \\
\text { sertifikatnya }\end{array}$ \\
\hline $\begin{array}{l}\text { Merekam } \\
\text { data } \\
\text { Magang/Skr } \\
\text { ipsi }\end{array}$ & $\begin{array}{l}\text { Mahasi } \\
\text { swa }\end{array}$ & $\begin{array}{l}\text { Mahasiswa yang telah } \\
\text { memiliki user,melakukan } \\
\text { perekaman data } \\
\text { Magang/Skripsi }\end{array}$ \\
\hline $\begin{array}{l}\text { Persetujuan/ } \\
\text { Approval } \\
\text { Kegiatan }\end{array}$ & Admin & $\begin{array}{l}\text { Admin melakukan } \\
\text { verifikasi dan persetujuan } \\
\text { perekaman data-data } \\
\text { kegiatan dan dokumen- } \\
\text { dokumen pendukungnya } \\
\text { yang telah direkam } \\
\text { dan diunggah oleh } \\
\text { Mahasiswa }\end{array}$ \\
\hline $\begin{array}{l}\text { Pengajuan } \\
\text { SKPI }\end{array}$ & $\begin{array}{l}\text { Mahasi } \\
\text { swa }\end{array}$ & $\begin{array}{l}\text { Mahasiswa yang telah } \\
\text { memiliki user, dan telah } \\
\text { merekam data } \\
\text { pendukung, melakukan } \\
\text { proses pengajuan SKPI }\end{array}$ \\
\hline $\begin{array}{l}\text { Persetujuan/ } \\
\text { Approval } \\
\text { Pengajuan } \\
\text { SKPI }\end{array}$ & Admin & $\begin{array}{l}\text { Admin melakukan } \\
\text { verifikasi dan persetujuan } \\
\text { / approval pengajuan } \\
\text { SKPI yang telah diajukan } \\
\text { oleh Mahasiswa }\end{array}$ \\
\hline $\begin{array}{l}\text { Pencetakan } \\
\text { SKPI }\end{array}$ & $\begin{array}{l}\text { Mahasi } \\
\text { swa }\end{array}$ & $\begin{array}{l}\text { Mahasiswa melakukan } \\
\text { pencetakan SKPI setelah } \\
\text { pengajuan disetujui oleh } \\
\text { Admin }\end{array}$ \\
\hline
\end{tabular}

Pada Activity Diagram Data Prestasi dan Penghargaan digambarkan mahasiswa melakukan perekaman data prestasi dan penghargaan, mengupload file pendukung, kemudian Admin melakukan persetujuan terhadap data prestasi dan penghargaan tersebut.

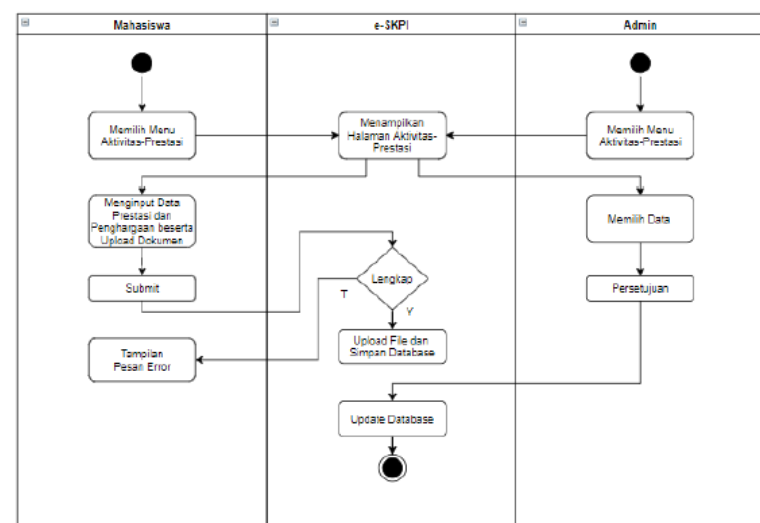

Gambar 3.2 Activity Diagram

\begin{tabular}{|l|l|}
\hline \multicolumn{1}{|c|}{ Actor } & \multicolumn{1}{c|}{ System } \\
\hline $\begin{array}{l}\text { User Mahasiswa } \\
\text { memilih menu Aktivitas- } \\
\text { Prestasi }\end{array}$ & $\begin{array}{l}\text { Browser menampilkan } \\
\text { halaman Prestasi }\end{array}$ \\
\hline $\begin{array}{l}\text { User Mahasiswa } \\
\text { melakukan perekaman } \\
\text { data prestasi dan } \\
\text { mengunggah dokumen } \\
\text { pendukung }\end{array}$ & \\
\hline $\begin{array}{l}\text { User Mahasiswa } \\
\text { menyimpan data } \\
\text { yang sudah direkam }\end{array}$ & $\begin{array}{l}\text { Sistem melakukan } \\
\text { verifikasi kelengkapan } \\
\text { data isian }\end{array}$ \\
\hline $\begin{array}{l}\text { Jika tidak ada pesan } \\
\text { error }\end{array}$ & $\begin{array}{l}\text { Sistem mengunggah } \\
\text { file dan menyimpan } \\
\text { data ke database, } \\
\text { selanjutnya } \\
\text { menampilkan halaman } \\
\text { Prestasi }\end{array}$ \\
\hline $\begin{array}{l}\text { User Admin memilih } \\
\text { menu Aktivitas-Prestasi }\end{array}$ & $\begin{array}{l}\text { Browser menampilkan } \\
\text { halaman Prestasi }\end{array}$ \\
\hline $\begin{array}{l}\text { User Admin memilih } \\
\text { data, kemudian } \\
\text { menyetujui kegiatan }\end{array}$ & $\begin{array}{l}\text { Sistem melakukan } \\
\text { perubahan data yang } \\
\text { dipilih dalam database } \\
\text { dan menampilkan } \\
\text { halaman Prestasi }\end{array}$ \\
\hline
\end{tabular}

Class diagram berikut menggambarkan hubungan antar objek-objek dari Aplikasi e-SKPI. Class user mempunyai relasi dengan class mahasiswa dan admin. Class Mahasiswa mempunyai relasi dengan class prodi, seminar, penghargaan, organisasi, pelatihan, magang, skripsi, dan pengajuan. Class Admin mempunyai relasi dengan class pengajuan. Class Pengajuan mempunyai relasi dengan class SKPI.

JISICOM (Journal of Information System, Informatics and Computing) http://journal.stmikjayakarta.ac.id/index.php/jisicom Telp.+62-21-3905050, e-mail: jisicom@stmikjayakarta.ac.id, jisicom2017@gmail.com 


\section{Journal of Information System, Informatics and Computing}

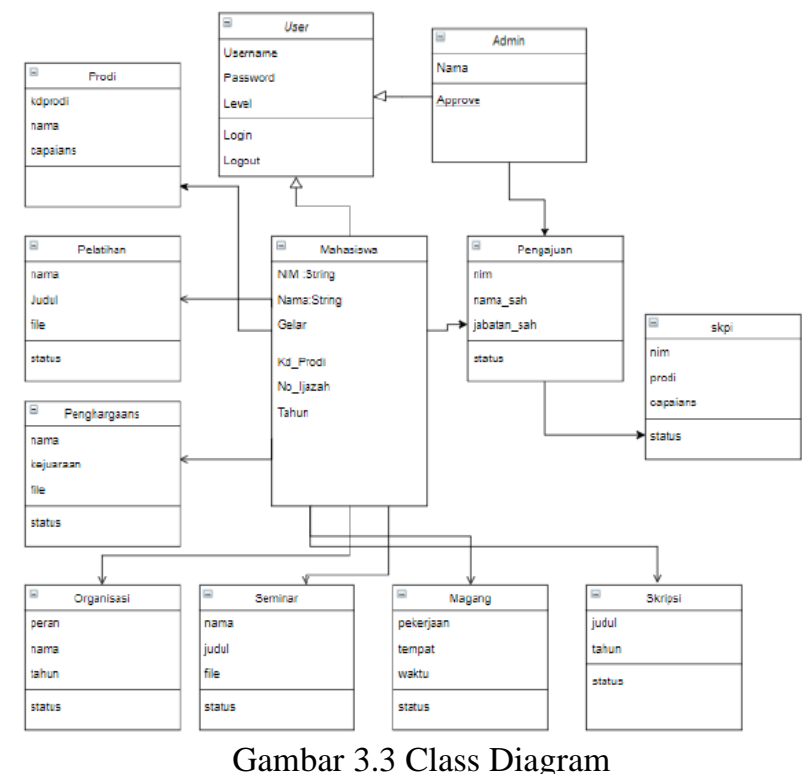

Tabel Keahlians ini berfungsi untuk menyimpan data keahlian yang dimiliki oleh mahasiswa. Struktur tabel Keahlians adalah sebagai berikut:

\begin{tabular}{|l|l|c|l|}
\hline \multicolumn{1}{|c|}{ Kolom } & Tipedata & Ukuran & Keterangan \\
\hline Id & BigInt & 20 & Auto \\
\hline Nim & Char & 8 & FK mhs.nim \\
\hline Nama & Varchar & 100 & \\
\hline Tempat & Varchar & 100 & \\
\hline Tahun & Char & 4 & \\
\hline File & Varchar & 150 & \\
\hline Status & Char & 1 & \\
\hline Created_at & Timestamp & & \\
\hline Updated_at & Timestamp & & \\
\hline
\end{tabular}

Aplikasi e-SKPI di-deploy ke dalam server STMIK Jayakarta dalam paket aplikasi web-server bernama XAMPP yang berisi Apache untuk menangani webservice dan MySQL untuk menangani manajemen database eskpi_stmik. Client atau pengguna dapat mengakses Aplikasi e-SKPI menggunakan web-browser dari komputer yang terhubung ke jaringan internet.

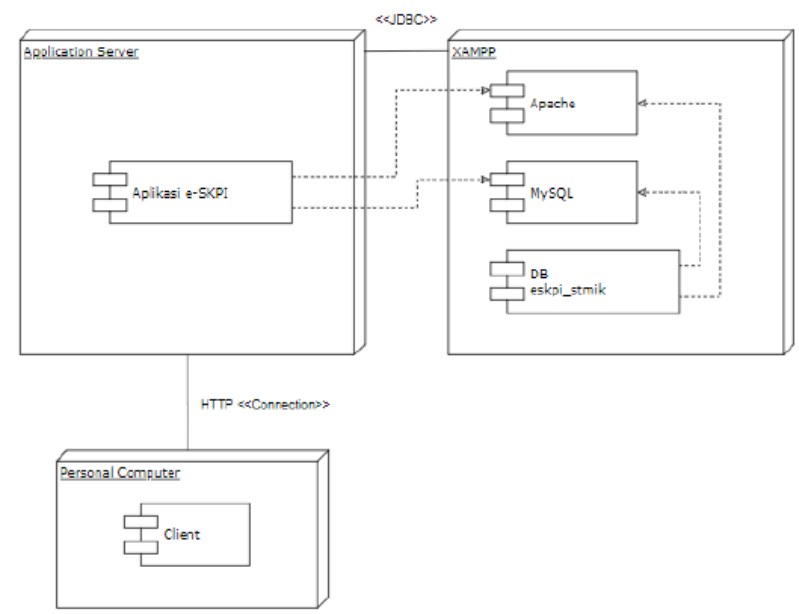

Gambar 3.4 Deployment Diagram

Rancangan HIPO (Hirarki Input Proses Output) Aplikasi e-SKPI ini terdiri dari 3 (tiga) menu utama, yaitu: Referensi, Aktivitas dan SKPI. Menu Referensi digunakan untuk menampung sub-sub menu referensi yang digunakan oleh aplikasi. Menu Referensi ini terdiri dari sub menu User, Mahasiswa, Kampus, Program Studi, Capaian. Menu Aktivitas digunakan untuk menampung sub-sub menu penginputan transaksi atau aktivitas dari pengajuan SKPI oleh mahasiswa. Menu Aktivitas ini terdisi dari sub menu Seminar, Prestasi, Peran Organisasi, Keahlian, Magang, Skripsi. Menu SKPI digunakan untuk menampung sub-sub menu proses pengajuan dan pencetakan dokumen SKPI. Menu SKPI ini terdiri dari sub menu Pengajuan, Approval, Cetak.

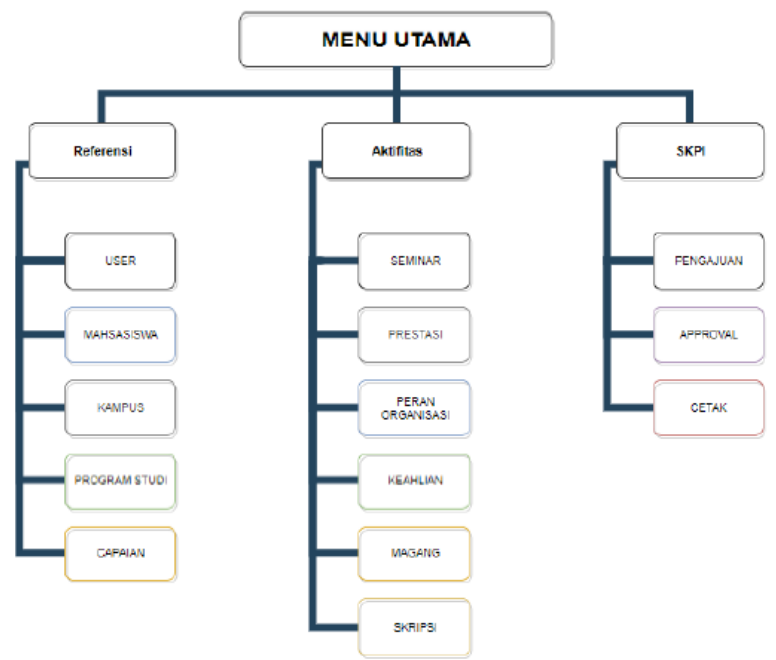

Gambar 3.5 Rancangan Hirarki Input Proses Output

JISICOM (Journal of Information System, Informatics and Computing)

http://journal.stmikjayakarta.ac.id/index.php/jisicom Telp.+62-21-3905050, e-mail: jisicom@stmikjayakarta.ac.id, jisicom2017@gmail.com 


\section{Journal of Information System, Informatics and Computing}

Halaman Desain Dashboard adalah halaman utama dari Aplikasi e-SKPI, terdiri dari: logo aplikasi e-SKPI, icon user dan namauser, kontainer yang berisi menudan sub menu dan bagian yang berisi informasi aplikasi.

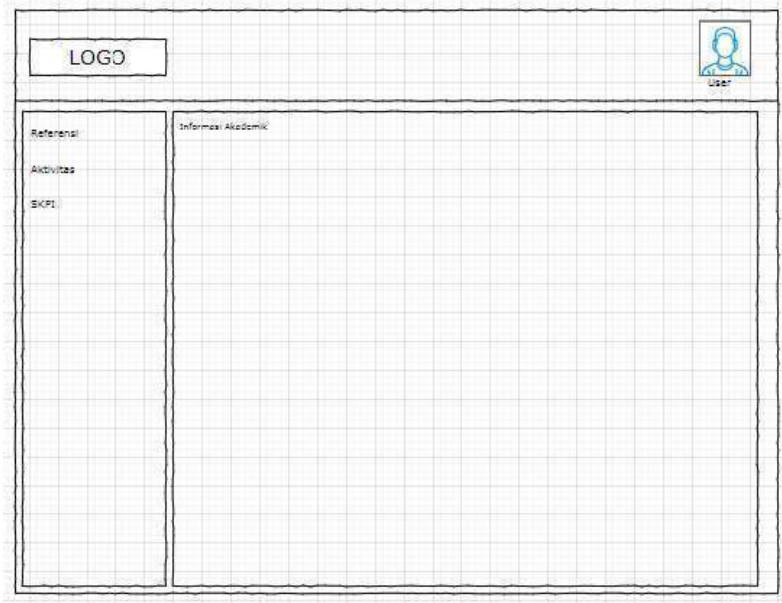

Gambar 3.6 Rancangan Tampilan Dashboard

Tampilan output/laporan dari Aplikasi e-SKPI ini merupakan hasil dari proses data dalam aplikasi berupa format cetakan dokumen SKPI. Rancangan laporan output Aplikasi e-SKPI adalah sebagai berikut:

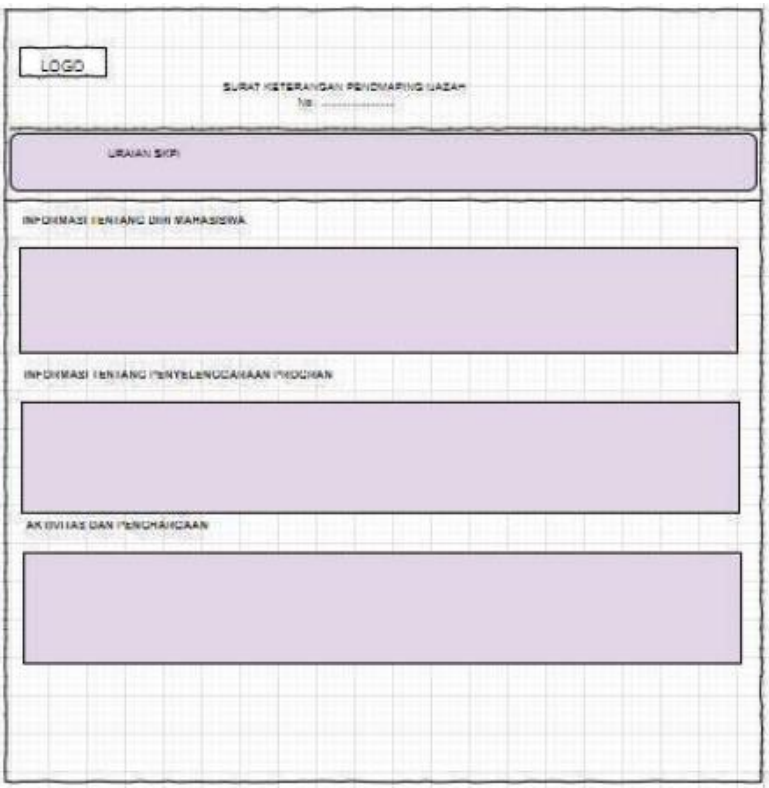

Gambar 3.7 Rancangan Hasil SKPI

Tahapan pengkodean membuat Aplikasi E-SKPI ini dengan bahasa pemrograman web PHP menggunakan framework Laravel dan sistem basis data menggunakan MySQL. Tampilan Dashboard ini adalah halaman utama dari Aplikasi e-SKPI. Dalam halaman ini ditampilkan informasi tentang Aplikasi e-SKPI. Pengguna dapat mengakses menu Referensi, Aktivitas, SKPI dan sub menunya di sebelah kiri.

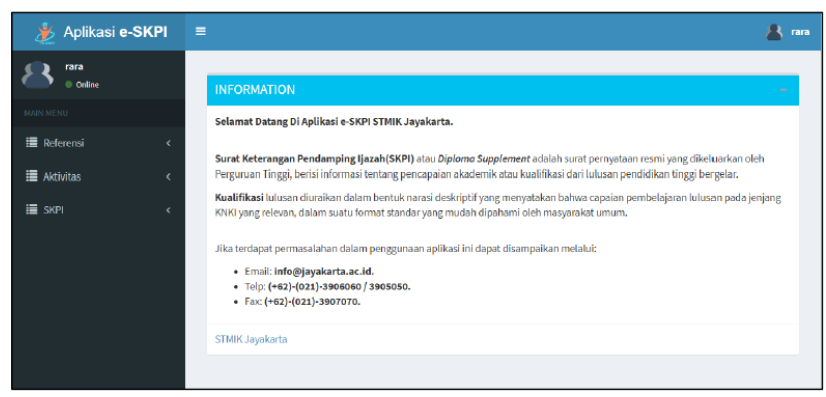

Gambar 3.7 Implementasi Tampilan Dashboard

Tampilan output atau layout laporan dari Aplikasi eSKPI ini adalah berupa tayangan dan cetakan dokumen SKPI dalam bentuk pdf, yang merupakan hasil akhir dari pengolahan data input yang masuk ke dalam sistem.

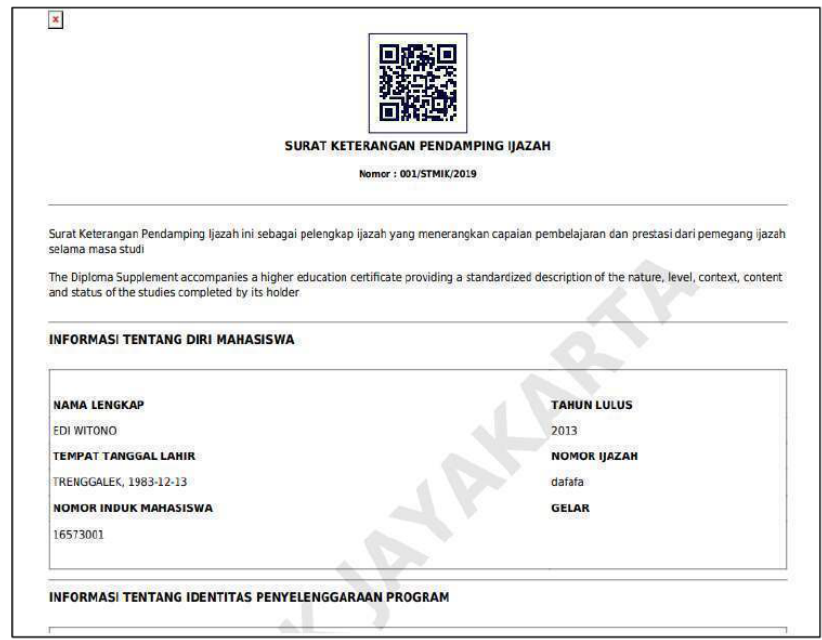

Gambar 3.8 Implementasi Hasil SKPI

\subsection{Pengujian}

Pengujian perangkat lunak ini menggunakan metode berdasarkan konsep pengujian black box. Pengujian black box mengidentifikasi kesalahan yang berhubungan dengan kesalahan fungsionalitas perangkat lunak yang tampak dalam kesalahan output, dan tidak terfokus pada source code sistem.

Pengujian black box ini memungkinkan untuk melakukan pengujian semua functional requirement dengan memasukkan input dan melihat hasil yang

JISICOM (Journal of Information System, Informatics and Computing)

http://journal.stmikjayakarta.ac.id/index.php/jisicom Telp.+62-21-3905050, e-mail: jisicom@stmikjayakarta.ac.id, jisicom2017@gmail.com 
diberikan oleh sistem. Metode pengujian ini dijalankan setelah sistem selesai dibangun.

\begin{tabular}{|c|c|c|c|}
\hline \multicolumn{4}{|c|}{ Kasus dan Hasil Uji } \\
\hline $\begin{array}{c}\text { Data } \\
\text { Masuk }\end{array}$ & $\begin{array}{c}\text { Yang } \\
\text { diharapkan }\end{array}$ & Pengamatan & $\begin{array}{c}\text { Kesimpul } \\
\text { an }\end{array}$ \\
\hline $\begin{array}{l}\text { Isian } \\
\text { data } \\
\text { lengka } \\
\mathrm{p}\end{array}$ & $\begin{array}{l}\text { Data dapat } \\
\text { tersimpan } \\
\text { dan muncul } \\
\text { di table } \\
\text { aktivitas. }\end{array}$ & $\begin{array}{l}\text { User dapat } \\
\text { Menyimpan } \\
\text { data dan } \\
\text { muncul di } \\
\text { table aktivitas }\end{array}$ & $\begin{array}{l}{[\mathrm{X}]} \\
\text { Diterima } \\
{[]} \\
\text { Ditolak }\end{array}$ \\
\hline $\begin{array}{l}\text { Isian } \\
\text { tidak } \\
\text { dilengk } \\
\text { api }\end{array}$ & $\begin{array}{l}\text { Data tidak } \\
\text { dapat } \\
\text { tersimpan } \\
\text { dan } \\
\text { muncul } \\
\text { isian yang } \\
\text { belum } \\
\text { dilengkapi } \\
\end{array}$ & $\begin{array}{l}\text { User tidak } \\
\text { dapat } \\
\text { menyimpan } \\
\text { data jika ada } \\
\text { isian yang } \\
\text { belum diisi } \\
\text { semua. }\end{array}$ & $\begin{array}{l}\mathrm{X}] \\
\text { Diterima } \\
{[]} \\
\text { Ditolak }\end{array}$ \\
\hline $\begin{array}{l}\text { Isian } \\
\text { NIM } \\
\text { tidak } \\
\text { terdaft } \\
\text { ar di } \\
\text { data } \\
\text { mahasi } \\
\text { swa } \\
\end{array}$ & $\begin{array}{l}\text { Data tidak } \\
\text { dapat } \\
\text { tersimpan } \\
\text { dan } \\
\text { menampilk } \\
\text { an } \\
\text { NIM tidak } \\
\text { valid }\end{array}$ & $\begin{array}{l}\text { User tidak } \\
\text { dapat } \\
\text { menyimpan } \\
\text { data dan } \\
\text { muncul } \\
\text { notifikasi } \\
\text { NIM } \\
\text { tidak valid } \\
\end{array}$ & $\begin{array}{l}{[\mathrm{X}]} \\
\text { Diterima } \\
{[]} \\
\text { Ditolak }\end{array}$ \\
\hline
\end{tabular}

\subsection{Penyebaran}

Penyebaran apliaksi berfungsi untuk menjalankan sistem aplikasi yang sudah dibuat, dan dapat diakses/digunakan oleh staf bagian akademik dan mahasiswa secara online melalui internet. Pada STMIK Jayakarta, saat ini telah tersedia web server dan Public IP yang nantinya dapat dipergunakan untuk hosting Aplikasi SKPI. Selanjutnya mahasiswa sebagai end user dapat mengakses Aplikasi SKPI tersebut melalui internet.

\section{KESIMPULAN}

Berdasarkan hasil penelitian, analiis, perancangan, pembuatan serta pengujian Aplikasi e-SKPI yang telah dilakukan pada STMIK Jayakarta, dapat diambil simpulan bahwa: aplikasi e-SKPI ini diharapkan dapat memenuhi kebutuhan penerbitan dokumen SKPI bagi para lulusan STMIK Jayakarta. Aplikasi e-SKPI ini, diharapkan dapat membantu semua pihak dalam mengelola dokumen, administrasi, monitoring dan validasi penerbitan SKPI. Mahasiswa sebagai pengguna dapat menginput kegiatan dan upload softcopy dokumen sebagai syarat penerbitan SKPI. Bagian akademik memverifikasi dokumen tersebut dan apabila sudah lengkap maka segera diterbitkan dokumen SKPI yang dapat diunduh oleh pihak mahasiswa.

Saran dari penulis terkait dengan pengembangan Aplikasi e-SKPI dan penelitian selanjutnya pada STMIK Jayakarta, agar dikembangkan aplikasi berbasis mobile untuk mempermudah pengguna dalam mengakses Aplikasi e-SKPI dan dilakukan integrasi dengan sistem akademik yang sudah ada, sehingga data mahasiswa tidak perlu direkam ulang, dan mahasiswa yang telah memiliki akun pada sistem akademik tidak perlu registrasi ulang pada Aplikasi e-SKPI ini.

\section{REFERENSI}

[1] Peraturan Presiden Republik Indonesia Nomor 8 tahun 2012 tentang Kerangka Kualifikasi Nasional Indonesia.

[2] Undang-Undang Republik Indonesia Nomor 20 Tahun 2003 Tentang Sistem Pendidikan Nasional.

[3] Peraturan Menteri Pendidikan Dan Kebudayaan Republik Indonesia Nomor 73 Tahun 2013 Tentang Penerapan Kerangka Kualifikasi Nasional Indonesia Bidang Pendidikan Tinggi.

[4] Peraturan Menteri Pendidikan Dan Kebudayaan Republik Indonesia Nomor 81 Tahun 2014 Tentang Ijazah, Sertifikat Kompetensi, Dan Sertifikat Profesi Pendidikan Tinggi.

[5] Rohman, Febri Nur. (2015). Pengembangan Aplikasi Web Pengolah Data Nilai Lomba Baris Berbaris Menggunakan Metodologi Extreme Programming. Yogjakarta: Universitas Negeri Yogyakarta.

[6] Simarmata, Janner. (2010). Rekayasa Perangkat Lunak. Yogyakarta: Andi Publisher.

[7] Prasetyo, Helmi Adi dan Yudho Yudhanto. 2018. Panduan Mudah Belajar Framework Laravel. Jakarta: PT Elex Media Komputindo.

[8] Fitriyanti, Sinta Eka. (2019). Sistem Informasi SKPI Sebagai Penunjang Kebutuhan Stakeholder. Universitas Jember.

[9] Suryani, D., Labellapansa, A., \& Gunawan, H. (2018). E-SKPI Fakultas Teknik Universitas Islam Riau. IT Journal Research and Development, 3(1), $115 \quad$ - 123. 


\section{Journal of Information System, Informatics and Computing}

https://doi.org/10.25299/itjrd.2018.Vol. 3(1).2091.

[10] Maiyana, Efmi, Teri Mengkasrinal. (2017). Pengembangan Sistem Informasi Surat Keterangan Pendamping Ijazah Berbasis Web dan Mobile Android, Prosiding Seminar Nasional Seminar Nasional Sistem Informasi dan Teknologi (SISFOTEK). ISSN 25973584 Vol.1 No.1. Organisasi Profesi Ikatan Ahli Informatika Indonesia (IAII) DPW Sumatera Barat.

[11] Def Ni, Fathur Ridha Fadly. (2019). Perancangan Sistem Informasi Surat Keterangan Pendamping Ijazah pada Politeknik Negeri Padang Berbasis Web. Jurnal Momentum
Vol.21, No. 1 e-ISSN: 2581-091X, Politeknik Negeri Padang.

[12] Anita Anita, Daniel Rudiaman Sijabat. (2017). Sistem Informasi Kompetensi Mahasiswa Guna Mendukung Lulusan Dalam Mencari Kerja, Jurnal Simantec ISSN: 2088-2130, Vol 6 No. 1. Department of Informatics Engineering, Faculty of Engineering, University of Trunojoyo Madura. https://doi.org/10.21107/simantec.v6i1.3196.

[13] Jayakarta.ac.id.(2019). Sejarah STMIK Jayakarta. Diakses pada Oktober 2020, dari https://jayakarta.ac.id/about/informasi-stmik. 